\title{
Utilização do método Famacha no diagnóstico clínico individual de haemoncose em ovinos no Sudoeste do Estado de Minas Gerais
}

\author{
Utilization of the Famacha method in individual clinic diagnostic of haemonchosis \\ in sheep of south-west of Minas Gerais State \\ Diana Cuglovici Abrão ${ }^{1 *}$; Silvana $\mathrm{Abrão}^{2}$; Carlos Henrique Cabral Viana ${ }^{3}$ Claudia Ribeiro do Valle ${ }^{3}$ \\ ${ }^{1}$ Departamento de Parasitologia, Instituto de Ciências Biológicas, Universidade Federal de Minas Gerais - UFMG \\ ${ }^{3}$ Pontifícia Universidade Católica de Minas Gerais - PUC Minas
}

${ }^{2}$ Laboratório Alpha, Análises Clínicas

Recebido em 21 de Setembro de 2009

Aceito em 30 de Setembro de 2009

\section{Resumo}

O objetivo deste estudo foi observar a eficácia do método Famacha no diagnóstico clínico individual de haemoncose em ovinos provenientes do Sudoeste de Minas Gerais. Cinquenta ovelhas mestiças Santa Inês foram avaliadas durante 5 meses quanto à coloração da mucosa conjuntiva (método Famacha), volume globular (VG), ovos por grama de fezes (OPG), escore corporal e alteraçóes clínicas. O escore Famacha observado variou de 1 a 3; o escore corporal de 2 a 5; o VG de 20 a 47\%; e o OPG de 0 a 7.750. As correlaçóes entre os parâmetros avaliados, exceto Famacha com escore corporal, foram altamente significativas $(\mathrm{P}<0,0001)$. O principal gênero identificado nas coproculturas foi Haemonchus (87 a 100\% do total de larvas, $\pm 93,5 \%$ ). Constatou-se redução de $87,33 \%$ na utilização de anti-helmínticos na propriedade. Conclui-se que o método Famacha, associado a outros métodos de diagnóstico, é ferramenta útil na detecção da haemoncose em ovinos.

Palavras-chave: Haemonchus sp., Famacha, volume globular, OPG.

\begin{abstract}
The aim of this study was to evaluate the efficacy of Famacha method in individual clinical diagnosis of haemonchosis in sheep from the south-west of Minas Gerais. Fifty crossbred Santa Inês ewes were evaluated during 5 months as for conjunctival mucous colour (Famacha method), Packed Cell Volume (PCV), Faecal Egg Counts (FEC), body score and clinic alterations. The score Famacha observed was from 1 to 3, the body score from 2 to 5, the PCV from 20 to $47 \%$, and FEC from 0 to 7,750. The correlations between the parameters evaluated, except Famacha with body score, were highly significant $(\mathrm{P}<0.0001)$. The main genus identified in the coprocultures was Haemonchus $(87-100 \%$ of total larvae, $\pm 93.5 \%$ ). We observed reduction of $87.33 \%$ in the use of anthelmintics on the property. It was concluded that the Famacha method, associated with other diagnostic methods, is a useful tool to detect hemonchosis in sheep.
\end{abstract}

Keywords: Haemonchus sp, Famacha, packed cell volume, FEC.

O parasitismo por helmintos gastrintestinais em ovinos é uma das principais causas de perdas na produção. Em decorrência dos gastos excessivos com anti-helmínticos e da mortalidade de fêmeas recém-paridas e de animais jovens, há diminuição da reposição do rebanho e dos índices reprodutivos desses animais. Além disso, perde-se na qualidade tanto da carne, quanto da lá. O controle do parasitismo em ovinos é feito, basicamente, com a utilização de

\footnotetext{
*Autor para correspondência: Diana Cuglovici Abrão Doutorado em Parasitologia

Departamento de Parasitologia do Instituto de Ciências Biológicas

Universidade Federal de Minas Gerais - UFMG

Av. Antônio Carlos, 6.627, ICB, sala 242, bloco E4 - Pampulha,

CEP 31270-901 Belo Horizonte - MG, Brasil

e-mail: diana_abrao@yahoo.com.br
}

anti-helmínticos e falhas nesse tipo de controle são os primeiros sinais do desenvolvimento da resistência anti-helmíntica.

Em 1992, foi criada uma tabela que representa as diferentes coloraçóes da conjuntiva ocular de ovinos, correlacionando-as com valores de hematócrito e o grau de infecção por Haemonchus contortus, denominado de método Famacha. Em estudos realizados para validar tal método, observou-se a diminuição no número de tratamentos realizados durante o ano na propriedade, permitindo selecionar indivíduos resistentes e resilientes aos helmintos (KAPLAN et al., 2004; MOLENTO et al., 2004).

$\mathrm{O}$ experimento foi realizado em propriedade localizada no município de Guaxupé, Sudoeste de Minas Gerais, de dezembro de 2005 a abril de 2006. Cinquenta borregas mestiças Santa Inês, 
naturalmente infectadas, foram avaliadas quanto ao escore de coloraçáo da mucosa (método Famacha), volume globular (VG), ovos por grama de fezes (OPG), escore corporal e alteraçôes clínicas. A coloração da mucosa foi avaliada semanalmente e os demais parâmetros, mensalmente. As fezes foram colhidas da ampola retal dos animais para a realização do OPG, segundo a técnica $\mathrm{Mc}$ Master modificada (GORDON; WHITLOCK, 1939). Com o pool de fezes de cada coleta, foi feita a coprocultura (ROBERTS; O'SULLIVAN, 1950) e a identificação das larvas (KEITH, 1953). O sangue foi colhido em tubos contendo anticoagulante EDTA e os valores de VG (\%) foram determinados pela técnica do micro-hematócrito por centrifugação. O escore corporal foi pontuado de acordo com Russel et al. (1969), e a coloraçáo da mucosa foi obtida a partir da escala pré-estabelecida pelo cartão Famacha. Os animais foram tratados com formulação a base de moxidectina $1 \%$ - anti-helmíntico já empregado na propriedade quando o OPG ultrapassou 3.500 ovos, ou quando apresentaram o escore Famacha igual ou superior a 3. Os dados de OPG, VG, Famacha e escore corporal foram submetidos à análise de correlação (SAS, 1982). Os dados climáticos foram obtidos nos arquivos da COOXUPÉ (Cooperativa Regional de Cafeicultores em Guaxupé Ltda.) e nos registros da propriedade.

No presente estudo, o gênero predominante identificado na coprocultura de cada coleta foi o Haemonchus, variando de 87 a 100\% das larvas, seguido por Cooperia (9 a 12\%) e Trichostrongylus (1\%). Em relação à sintomatologia clínica, apenas um animal apresentou edema submandibular. $\mathrm{O}$ escore de mucosa observado (Famacha) variou de 1 a 3; o escore corporal de 2 a 5; o VG de 20 a 47\%; e o OPG de 0 a 7.750. As correlaçôes calculadas entre os parâmetros avaliados estão representadas na Tabela 1. Todas as correlaçóes, exceto Famacha com escore corporal, foram altamente significativas $(\mathrm{P}<0,0001)$, concordando com diversos estudos (KAPLAN et al., 2004; MOLENTO et al., 2004; DEPNER et al., 2007).

Conforme observado no presente experimento, a correlação dos escores observados para o método Famacha com a infecção por $H$. contortus foi constatada como em outros países (KAPLAN et al., 2004) e no Brasil (MOLENTO et al., 2004). Molento et al. (2004) afirmam que os valores do VG correspondentes aos graus Famacha são: acima de 28\%: grau 1; entre 23 e 27\%: grau 2; entre 18 e 22\%: grau 3; de 13 a 17\%: grau 4; e abaixo de $12 \%$ : grau 5. Considerando-se que nem sempre o grau Famacha corresponderá ao seu valor de referência no hematócrito, o método deve ser utilizado em conjunto com outra técnica de diagnóstico de parasitose, como o OPG, por exemplo. Além disso, os animais se encontravam em bom estado nutricional, sendo alimentados com dieta de aproximadamente

Tabela 1. Coeficientes de correlação entre as variáveis Famacha $\times \mathrm{VG}$, Famacha $\times$ OPG, Famacha $\times$ Escore corporal, VG $\times$ OPG, OPG $\times$ Escore corporal e Escore corporal $\times$ VG durante todo o período experimental (de dezembro de 2005 a abril de 2006).

\begin{tabular}{lccc}
\hline & VG & OPG & Escore corporal \\
\hline Famacha & $-0,45^{*}$ & $0,36^{*}$ & $-0,20$ \\
VG & & $-0,45$ & $0,41^{*}$ \\
OPG & & & $-0,31^{*}$ \\
\hline
\end{tabular}

* coeficientes significativos estatisticamente $(\mathrm{P}<0,0001)$.
13\% de proteína bruta. A suplementação proteica auxilia na resposta imunológica contra os parasitos (COOP; KYRIAZAKIS, 2001), interferindo nos resultados encontrados quanto à correlação do OPG com o Famacha $(r=0,36)$, considerada média a baixa. Em locais onde $H$. contortus exerce baixa pressão parasitária, as correlaçóes entre Famacha, VG e OPG sáo baixas (Gauly et al., 2004). Segundo Amarante et al. (1998), verifica-se relação inversa entre a carga parasitária e os valores de VG em ovelhas, conforme observado neste experimento. Sendo Haemonchus o gênero mais prevalente neste experimento e em outros realizados com ovinos, este achado era esperado.

Durante o período experimental, a umidade relativa do ar variou de 14,9 a $88,2 \%$ ( $\pm 59,9 \%)$; as temperaturas mensais, de 5 a $28^{\circ} \mathrm{C}\left( \pm 20,7^{\circ} \mathrm{C}\right)$; e os índices pluviométricos foram de 49 a $230 \mathrm{~mm}( \pm 149,4 \mathrm{~mm})$, sendo as maiores precipitaçóes observadas em fevereiro (198,2 mm) e março (167 mm) de 2006. Apesar de terem sido observadas reduçóes nas contagens de OPG, nos meses mais secos do período experimental, essa ocorrência não foi atribuída às condiçóes climáticas. Provavelmente, a queda nas contagens de OPG ocorreu em decorrência do desenvolvimento de resposta imunológica pelos animais, que eram mantidos em boas condiçóes nutricionais.

Em fevereiro de 2006, doze animais (24\% do rebanho) foram tratados com anti-helmíntico. Em março de 2006, apenas cinco (10\% do rebanho) necessitaram de tratamento e, em abril de 2006, dois animais que já haviam sido tratados em fevereiro foram dosificados novamente, totalizando 19 tratamentos seletivos. Comparando-se com o mesmo período do ano anterior, quando foram realizados 150 tratamentos supressivos, houve uma redução de $87,33 \%$ na utilização de anti-helmínticos. Sabe-se que a resistência múltipla dos parasitos às drogas vem aumentando gradativamente e tornou-se um dos principais entraves no desenvolvimento da ovinocultura em diversos lugares do mundo (KAPLAN, 2004). Portanto, o método Famacha pode ser utilizado como auxiliar no emprego do tratamento seletivo, em situaçóes em que há alta prevalência de $H$. contortus, visando à exposição mínima dos helmintos aos medicamentos e diminuindo, assim, a pressão de seleção sobre estes.

O experimento foi realizado em um período crítico do ano, quando há alta taxa de contaminação das pastagens por ovos de helmintos e o desafio parasitário é maior. Diante das correlaçóes encontradas e da diminuição da utilização de anti-helmínticos, conclui-se que o método Famacha é ferramenta útil no diagnóstico clínico individual da haemoncose em ovinos, desde que utilizado integrado a outros métodos de diagnóstico parasitário, como o OPG. Dessa forma, pode-se estabelecer um controle adequado para cada situação.

\section{Referências}

AMARANTE, A. F. T. et al. Nematode egg counts, packed cell volume and body weight as parameters to identify sheep resistant and susceptible to infections by gastrointestinal nematodes. ARS Veterinária, v. 14, n. 3, p. 331-339, 1998.

COOP, R. L.; KYRIAZAKIS, L. Influence of host nutrition on the development and consequences of nematode parasitism in ruminants. Trends in Parasitology, v. 17, n. 7, p. 325-330, 2001. 
DEPNER, R. A. et al. Growth performance in naturally infected lambs with gastrointestinal nematodes under selective treatment with Famacha method and preventive treatment. Archives of Veterinary Science, v. 12, n. 3, p. 32-37, 2007.

GAULY, M.; SCHACKERT, M.; ERHARDT, G. Use of Famacha Scoring System as a diagnostic aid for the registration of distinguishing marks in the breeding program for lambs exposed to an experimental Haemonchus contortus infection. Deutsche tierärztliche Wochenschrift, v. 111, n. 11 , p. 430-433, 2004.

GORDON, H. M.; WHITLOCK, H. V. A new technique for counting nematode eggs in sheep faeces. Journal of Council of Science and Industry Research in Australia, v. 12, n. 1, p. 50-52, 1939.

KAPLAN, R. M. et al. Validation of the Famacha eye color chart for detecting clinical anemia in sheep and goats on farms in the southern United States. Veterinary Parasitology, v. 123, n. 1-2, p. 105-120, 2004.
KEITH, R. K. The differentiation of the infective larvae of some common nematode parasites of cattle. Australian Journal of Zoology, v. 1, n. 2, p. 223-235, 1953.

MOLENTO, M. B. et al. Método Famacha como parâmetro clínico individual de infecção por Haemonchus contortus em pequenos ruminantes. Ciência Rural, v. 34, n. 4, p. 1139-1145, 2004.

ROBERTS, F. H. S.; O'SULLIVAN, J. P. Methods for egg counts and larval cultures for strongyles infesting the gastrointestinal tract of cattle. Australian Journal of Agricultural Research, v. 1, n. 1, p. 99-102, 1950.

RUSSEL, A. J. F.; DONEY, J. M.; GUNN, R. G. Subjective assessment of body fat in live sheep. Journal Agricultural Science, v. 72, n. 3 , p. 451-454, 1969.

SAS INSTITUTE. SAS user's guide: statistics. Version 5. Cary, 1982. 